\title{
Exhumar, escribir, traducir (a propósito de Clamor, versión en español de Glas de Jacques Derrida)
}

y Entrevista a Cristina de Peretti, Luis Ferrero Carracedo, Fabio Vélez Bertomeu, Cristina Rodríguez Marciel, Delmiro Rocha. Por Analía Gerbaudo / Universidad Nacional del Litoral - conicet

Deslumbrante tapa roja. En grandes letras de contorno negro, el título escogido por Derrida, en francés, para su libro: Glas. En letras más pequeñas, también en negro y también con mayúsculas, su versión al español: Clamor. Los nombres de Jacques Derrida y los de la editorial La oficina que se atreve con semejante emprendimiento, en blanco.

En la solapa, una primera lectura del texto a cargo de los responsables de su traducción. Una lectura que se replica en el sitio Web al que se envía desde la hoja de los créditos: en la página oficial del grupo Decontra, el Seminario de Investigación Permanente sobre Jacques Derrida dirigido por Cristina de Peretti desde la Universidad Nacional de Educación a Distancia (UNED), se aloja lo que se podría considerar la segunda parte de este libro, algo así como su segundo tomo en acceso abierto y en soporte digital (http://decontra.es/clamor-glas/). Algo que cumple en parte un sueño que Delmiro Rocha confesaba en una primera entrevista realizada al equipo de traductores coordinado por Cristina de Peretti y Luis Ferrero Carracedo: Rocha fantaseaba con la posibilidad de distribuir Glas gratuitamente por Internet «bajo las características de software libre con una licencia creative commons y que cada uno se lo imprima en su casa con este formato». Y agregaba, a contrapelo de todas las estrategias del mercado: "y en lugar de 50 euros, valdrá 5».

Un equipo que ya entonces, en 2008 , llevaba ańos trabajando sobre este proyecto que encuentra, por fin, una editorial que lo edite y lo ponga en circulación en español en 2015 respetando además maquetación y tipografía exigidos por estos «tejedores reales». Un equipo integrado por Beatriz Blanco Vázquez, Patricio Peñalver Gómez, Fernando Rampérez Alcolea, José María Ripalda Crespo, Delmiro Rocha Álvarez, Cristina Rodríguez Marciel, Manuel Vázquez García y Francisco Javier Vidarte con la colaboración de Fabio Vélez Bertomeu.

A.G.: En esta conversación me importa reponer un dato que Cristina de Peretti revelaba en la entrevista que le hice por 2008 con el objeto de ampliarlo: entonces 
contaba que hacia finales de los 80 habían empezado esta tarea descomunal de traducir Glas junto a Luis Ferrero Carracedo. Ella se encargaba de la columna de Genet y su compańero, de la de Hegel. Un trabajo que queda inconcluso, que se realizaba con mucho esfuerzo (de Peretti estrenaba entonces las primeras computadoras, la de los grandes disquetes, mientras Ferrero recurría aún a la máquina de escribir) y que se retoma en 2005 ante la posibilidad de diseńar un proyecto de investigación dedicado a esta titánica tarea.

Durante mi estadía de investigación en la UNED en 2008, de Peretti me comentó la dinámica seguida por el equipo durante todos esos años de trabajo; la increíble y tenaz y sostenida tarea que llevó a esta im-posible traducción. Cristina, me gustaría que pudieras reponer algo de ese tejido colectivo: cómo se organizaban, con qué frecuencia se reunían, cómo trabajaban.

Cristina de Peretti: No empezamos a trabajar en este proyecto en 2005 sino una vez que el Ministerio de Educación y Ciencia nos confirmó la concesión del proyecto de investigación I+D. Pero no recuerdo exactamente si comenzamos en octubre de 2006 o a principios de 2007 (aunque veo que Luis Ferrero sí que recuerda la fecha exacta). En cualquier caso, lo primero que hicimos, evidentemente, fue recuperar la traducción de Glas que, como bien recuerdas, realizamos Luis y yo a finales de los años 1980, y que terminamos, pero de la que no llegamos a revisar más que una pequeńa parte. Recuperamos, pues, esa antigua traducción y la convertimos en el soporte a partir del cual emprendimos el trabajo. Durante ese primer curso 2006-2007 organizamos dos grupos de traducción: uno para la columna de Hegel, coordinado por Paco Vidarte (Luis Ferrero, por razones laborales, no pudo incorporarse al equipo hasta más adelante), y otro para la columna de Genet, coordinado por mí. Cada grupo se reunía normalmente una vez por semana y todos los miembros del grupo traíamos leídas unas io páginas de esa antigua traducción con las anotaciones y observaciones que habíamos considerado pertinentes y que, en la reunión, discutíamos entre nosotros hasta lograr una traducción que nos convenciese a todos. Ni que decir tiene que ni mucho menos conseguíamos nunca revisar esas io páginas que traíamos preparadas de casa ni siempre estábamos todos de acuerdo con la traducción «momentáneamente» adoptada que, a veces, ni siquiera satisfacía a ninguno de nosotros. En esos casos, solíamos continuar y, en la(s) siguiente(s) reunión(es), tras habernos devanado un poco más los sesos cada uno por su cuenta durante esa(s) semana(s) posterior(es), volvíamos sobre nuestras diferencias o sobre nuestra común insatisfacción hasta que terminábamos por encontrar algo que mereciera la aprobación de todos... o, al menos, de la mayoría.

En septiembre de 2007, Paco, ya enfermo, tuvo que abandonar todas sus actividades profesionales. Decidimos entonces constituir un solo grupo para acabar esa primera revisión-traducción de la columna de Genet y retomar después la de Hegel. La mecánica siguió siendo la misma: reuniones semanales, preparación por parte de cada uno, discusiones comunes, etc. En octubre de 2008, Luis Ferrero se unió por fin al grupo. 
Por descontado, tras esa primera revisión-traducción de ambas columnas, vinieron otras cuantas más, con el fin de controlar, comprobar y depurar lo más posible la traducción. Y, aun así, después de que, tras todos esos ańos de trabajo en común, diésemos por finalizada la traducción y poco a poco se fueran marchando de Madrid o fueran retomando sus otros quehaceres los demás miembros del grupo de traducción, Luis y yo — quizá debido a un afán perfeccionista exacerbado - seguimos revisando una y otra vez la traducción. Luis, que sin duda tiene mucho más desarrollado el sentido archivador que yo, conserva todavía en su ordenador ¡las io versiones revisadas que hemos llegado a tener de ambas columnas de Clamor!

Luis Ferrero Carracedo: Mi relación con Cristina de Peretti comenzó mediada la década de los 70 del pasado siglo y se consolidó en un grupo de trabajo creado en 1977 por Ángel Currás en la Facultad de Filosofía de la Complutense. Cristina centró su tarea investigadora en la obra de Jacques Derrida mientras yo lo hacía en la de Gilles Deleuze (fruto de ello serían nuestras tesis doctorales dedicadas a sendos pensadores). Este camino paralelo no sólo no fue óbice para un trabajo en común, sino todo lo contrario. Diversas circunstancias, y el tesón de Cristina, nos llevaron a realizar un trabajo conjunto sobre la recepción del pensamiento de Derrida en España mediante una labor crítica de las traducciones al castellano de sus obras. Y hablando de traducciones, ahí estaba Glas, publicada en 1974, que nos fascinaba, pero no se había traducido ni había indicios de que alguna editorial tuviera el propósito de hacerlo. Nos parecía un auténtico sinsentido que una obra tan singular no pudiera ser accesible a los lectores de lengua castellana que no pudieran leerla en su versión original. En aquellos momentos apareció la traducción al inglés de John Leavy y Richard Rand (I986), con su GLASsary, de los que Cristina consiguió, por medio de un amigo que se encontraba por aquella época en Berlín, un ejemplar fotocopiado. Curiosamente llevan el sello de la Universidad de Konstanza. Si los norteamericanos han sido capaces de hacer una traducción, ¿por qué no podemos intentarlo nosotros?, nos preguntábamos. Era un reto difícil, pero ilusión no nos faltaba. La publicación de un monográfico de la revista Anthropos sobre Derrida en febrero de 1989 significó un momento decisivo. La propia editorial Anthropos nos mostró su interés por llevar a cabo la edición, si lográbamos una ayuda económica. Así queda constancia en la Carta que dirigimos a Jean Categglio, por entonces director del Libro en el Ministerio de Cultura francés. En ella exponíamos, junto a las dificultades de la traducción y de la edición, nuestro propósito: la traducción de Glas no podía abordarse como un simple trabajo de traducción; exigía, al igual que la traducción inglesa publicada en Estados Unidos, un trabajo de investigación suplementaria: redacción de numerosas notas de traducción, una suerte de introducción a la lectura, y un glosario detallado. Labor de tres o cuatro años como mínimo, pensábamos. Y con la ilusión de una repuesta positiva (que nunca llegó a tener lugar) nos pusimos manos a la obra. Cristina traducía la columna de Genet, yo 
la de Hegel: nos reuníamos los fines de semana en el apartamento de Cristina, en el que Nietzscha (una perra muy inquieta) me recibía siempre con gran alborozo. Corregíamos en paralelo nuestros textos. Las dificultades se apilaban por doquier. Comenzando por el primer párrafo de la columna de Hegel (quoi $d u$ reste...?). Era una auténtica lucha con el lenguaje, porque desde el principio nos propusimos no intercalar ningún vocablo francés en la traducción. Pero ¿qué hacer con tombe, déjà, seing, glande... y tantos «juegos» derridianos que el francés hace posible, incluso - para mayor desesperación nuestra - en el plano fónico, pero que en castellano resultan imposibles? Glas exigía un tipo de traducción que se salía de lo corriente: exigía una traducción creativa, intensiva, que convierte la traición en su más profunda fidelidad. Las revisiones conjuntas avanzaban con lentitud, pero no dejábamos de sentir gran satisfacción cuando encontrábamos una solución que nos parecía aceptable ante ciertos desafíos. Algunas soluciones de entonces han permanecido; otras han sido reemplazadas por soluciones más potentes e ingeniosas. La publicación en Anthropos, en I992, de las primeras páginas, con las notas pertinentes significó el final de esta primera etapa de trabajo a dos. Para entonces habíamos traducido por separado las columnas completas, con excepción de las cartas de Hegel. Las revisiones conjuntas sólo alcanzaron la página I07, con un final de párrafo en la columna de Hegel sin duda premonitorio, porque la labor hasta entonces realizada, que quedó interrumpida por diversas razones de tipo profesional, murió, como Cristo, "con la convicción de que su designio no caería en saco roto» (Clamor, Hegel, I07:28-29).

Pasaron los tres días sepulcrales, que en este caso fueron trece años, de bajada a los cajones del olvido de aquellos archivos (en disco blando todavía), tapuscritos y manuscritos, y de nuevo, una vez más, el tesón de Cristina de Peretti resucitó el empolvado proyecto de la traducción de Glas. Esta vez sí, para, una vez resucitado, llegar a alcanzar felizmente un cuerpo «clamoroso». La concesión, por parte del Ministerio de Educación de Espańa, del proyecto I+D para llevar a cabo la traducción iba a hacer posible lo imposible. Pero no ya con un trabajo de dos, sino de un gran equipo de investigadores (cargados unos de ya larga experiencia e inquietos e ilusionados otros con su restallante juventud) bien preparados para llevar a cabo la tarea. Rescatamos nuestras traducciones (por mi parte, trasladé a soporte informático la parte dactilografiada — con mi ya arrinconada Olympiay también la otra gran parte que todavía mantenía manuscrita), y el equipo comenzó su labor de revisión y de corrección de lo ya hecho. La reunión inicial del grupo tuvo lugar el i2 de febrero del año 2007. Por razones laborales no pude incorporarme al trabajo del equipo hasta el otońo de 2008. Nuestro recordado Paco Vidarte, un joven lleno de energía e ilusiones, tomaba con Fernando Rampérez las riendas de la revisión de la columna de Hegel. En un e-mail del I de marzo de 2007 me escribía Paco: «Ya nos hemos reunido dos veces. Desesperante. Dos páginas cada reunión. Ya encontraremos una velocidad de crucero adecuada». Cuando en el otońo de 2008 me incorporé al grupo de revisión de la traducción ya no tuve la suerte de trabajar con Paco. Nos había dejado el 29 de enero de 
2008. La primera reunión de trabajo a la que asistí tuvo lugar el 27 de octubre de ese año. Me encontré con la columna de Genet ya revisada - aunque aquello era siempre un work in progress, tanto en una columna como en la otra- y con gratas sorpresas en la litigiosa tarea de búsqueda del término o la expresión adecuada para verter al español el lenguaje derridiano. Comenzando por el título: Clamor. De él se hablará más tarde. Y después de él, toda una retahíla de vocablos y expresiones nuevos. Sobre todo dos me llamaron entonces la atención: «no deja ya de» (déjà), y "empalmar» (bander): solución ingeniosa, con firma de Cristina de Peretti, la primera; uso acertado del argot, con firma de Delmiro Rocha, la segunda. Para las citas y las cartas de Hegel tomamos como texto base la traducción hecha expresamente por José María Ripalda del original alemán — siempre teniendo en cuenta por nuestra parte la traducción francesa utilizada por Derrida- Nos reuníamos las mañanas de los lunes (alguna vez también los jueves): Cristina de Peretti, Fernando Rampérez, Beatriz Blanco, Delmiro Rocha, Cristina Rodríguez Marciel, Fabio Vélez y yo mismo. Llevábamos nuestras propuestas, se discutían y se tomaba la decisión por mayoría. Para mí fue una experiencia apasionante, un verdadero trabajo en equipo, en el que cada uno aportaba lo mejor de sí mismo: el «velo palatino», o el «en derredor tras el telón» de Fabio, el afán por los «restos» de Bea, y no puedo olvidar el «sin sí» que aparece en las págs. 266 y 267 por el empeño de Fernando y su aportación de la «campana arpada» (Hegel, 278:2). No recuerdo cómo surgió lo de "verdaderomiente fin(gid)o», una auténtica filigrana semejante a la de Derrida, o lo de «p(r)ensar» y «ma(d)r(e) (ingeniosas formas de concentrar penser y panser, mer y mère, que en francés suenan prácticamente lo mismo). A veces no quedaba más remedio que poner uno a continuación del otro el doble significado de la expresión para el oído del oyente: Harcamone d'or («Harcamone de oro (duerme)»). Era un taller de traducción y de pensamiento, con afán de estilo, arriesgando cuando era preciso, «neologizando» como hace Derrida («margenar», "parántesis»). Era, como diría Alfred Gudeman, una orgía del lenguaje al modo estoico. Y de paso logramos dos descubrimientos, que no lograron las versiones inglesa, alemana e italiana sobre los que hablaré más adelante. Además de una labor de traducción allí se sentía uno, pues, en un verdadero taller de creación: largas horas que se pasaban en un abrir y cerrar de ojos. No cabe duda de que todo aquello era movido "por amor de Derrida». La última reunión del equipo de traducción — desde mi incorporación pasaron de la treintena- tuvo lugar el ir de mayo de 20Io. Después ya vino el último trabajo de pulimento, de puesta a punto, con una maquetación en word y en pdf para que se viera relucir el trabajo hecho; trabajo que no terminó hasta el día en que Joaquín Gallego, mediado ya agosto de 20I5, envió los ferros a la imprenta para la edición definitiva.

Delmiro Rocha: Solamente ańadir, por alusiones, que ese «sueño» al que apuntas, que por aquel entonces afloraba como una cuestión más bien pragmática pues ninguna editorial quería hacerse cargo de este Clamor, es una cuestión pre- 
sente en las propias reflexiones de Derrida acerca de la bibliocultura y de las formas heredadas de la publicación, de la autorización, del control, etc. No sólo asistimos al fin del libro, tal y como Derrida lo entiende, como final de una totalidad de sentido, sino también al fin del libro como formato, como forma, como objeto secular determinado, venerado y quizá venerable, pero que resiste a duras penas, especialmente si se trata de textos como el que aquí nos atañe, las embestidas y exigencias del mercado. Este debate está abierto desde hace tiempo y promete mucha «tinta» todavía, pero lo que cada vez tenemos menos claro es en qué formato y bajo qué condiciones vamos a acceder a él. Dicho esto, me cuesta pensar una edición mejor de esta obra que la realizada por La Oficina. No solo cumple los más altos estándares de profesionalidad y rigor, sino que es hermosa, una hermosa obra. Gracias, por lo tanto, a Arturo Leyte y a Joaquín Gallego. Sin ellos, probablemente no estaríamos realizando esta segunda entrevista.

A.G.: Volvamos al título y a la tapa. También en 2008 habíamos conversado sobre la decisión de traducirlo marchando a contrapelo de las versiones al inglés, al italiano y al alemán que sólo mantienen el nombre de Glas sin arriesgar más allá (salvo el despunte que ensaya la alemana). Mi pregunta aquí es doble: quisiera que retomaran la poética y etimológica explicación respecto de por qué elegir Clamor frente a la versión más literal de «tañido fúnebre» que Cristina (y entiendo, también Luis) habían suscripto en los inicios, en los años 80 . Y a la vez, por qué hacer ese doble juego de "más de una lengua» al colocar el título en francés y en español, juntos, en la tapa.

C.P.: Voy a tratar de ser bastante más breve que en mi respuesta anterior. Es cierto que, en los años I980, Luis y yo pensamos en traducir glas por «tañido fúnebre» pero también es cierto, como ya he apuntado, que esa primera traducción la revisamos muy poco, muy parcialmente y el título quedó así de momento. Cuando retomamos la traducción muchos años más tarde, descubrimos un buen día, por pura casualidad (Clamor y su publicación no han dejado de ser, por distintos motivos, todo un cúmulo de azares) que «clamor» también se utilizaba para el «tañido fúnebre». Consultamos el Diccionario de la Real Academia Española de la lengua y comprobamos que, en efecto, una de las acepciones - aunque no la primera - de «clamor» es precisamente esa: el toque de campanas por los difuntos, el tañido fúnebre, y «clamorear» es doblar, tocar a muerto. Pero, además de coincidir esta significación con la del glas francés, "clamor» tiene otro aliciente más — no menos importante si cabe - y es que combina, al igual que glas, la consonante líquida «l» con otra consonante gutural, en este caso la «c» en lugar de la «g» francesa. Y no hay que olvidar que en Glas Derrida probablemente hace tantos malabarismos lingüísticos con el sonido "gl» como con el sonido «cl». Así que el término «clamor» fue uno de esos «acontecimientos translaticios» con los que los traductores nos volvemos locos de alegría cuando surgen ya sea por casualidad ya sea gracias a la constancia. 
En cuanto a «ese doble juego de "más de una lengua”» — como tú lo llamas— consistente en colocar juntos, en la portada de la traducción española, el título francés y el título español del libro, es curioso... porque ¡claro que nosotros habíamos pensado ya en ello! pero, antes de que lo sugiriésemos, se le ocurrió a su vez a Joaquín Gallego, el genial diseñador de Clamor (tanto de su cubierta como de la maquetación de sus columnas), que desconocía por completo la importancia que para Derrida siempre ha tenido ese «más de una lengua». Obviamente, cuando nos propuso poner ambos títulos en la tapa, le dijimos que nos parecía perfecto. Aprovecho aquí la ocasión para darle las gracias una vez más a Joaquín no sólo por el magnífico y cuidadísimo trabajo que ha realizado tanto con el exterior como con el interior de Clamor sino también por su comprensión y su paciencia con Luis y conmigo durante ese largo, tórrido y laborioso verano de 20I5. Tanto él como Luis, cuando lean estas líneas, sabrán muy bien de lo que estoy hablando...

L.F.C.: La traducción de Glas por «Tañido fúnebre» es ciertamente la más literal, que adoptamos como una necesidad. Eran muchos los inconvenientes que nos planteaba dicha traducción, la cual, de todos modos, nos sonaba mejor que «toque de muerto", o "toque a muerto». Mantener sin más el título francés tampoco tenía mucho sentido para un lector de lengua castellana. Al publicar las primeras páginas en Anthropos no habíamos encontrado otra alternativa. Pero esta llegó un día por casualidad, como nos cuenta Cristina de Peretti, desgraciadamente en mi ausencia pues me hubiera gustado participar en el evento. Cuando me incorporé al trabajo de traducción me encontré ya con «clamor». En ese momento, como primera impresión sin reflexión alguna, me pareció una ocurrencia, una buena ocurrencia, algo como para impresionar al lector. Pero enseguida comprendí que era algo más que una ocurrencia: su descubrimiento había sido un verdadero acontecimiento y optar por este título fue una decisión genial. Al cotejar Clamor y Glas se ve perfectamente la razón de la elección, el pleno sentido de la misma, aparte del juego «cl» de suma importancia en el libro. Hay un verso de Poe muy ad hoc: "In the clamor and the clangor of the bells» (Clamor, Genet, I76i:I7) con el secuente discurso de Derrida: "Oíd el clamor de las campanas _ ¡campanas de hierro! ¡Qué mundo de pensamiento solemne comporta su monodia! ¡En el silencio de la noche, cómo tiritamos de espanto! con la melancólica amenaza de su tono. Pues cada sonido que flota, de la herrumbre fuera de sus gargantas- es un gemido" (Clamor, Genet, I76i:20-25).

Y a propósito del doble juego de «más de una lengua» quiero hacer una pequeña reflexión. Sin duda el doble título implementa ese juego. Pero, además, en la elección de Clamor podemos ver otro juego más profundo: el «más de una lengua» intensivo, aiónico, transtemporal. Clamor nos sumerge en la profundidad del tiempo que subyace en el lenguaje: en el tiempo sin tiempo. Es como un palimpsesto que trae el pasado al presente y lleva el presente al pasado. Su presencia en el título nos retrotrae a uno de sus usos antiguos, que recoge hermosamente 
Sebastián de Covarrubias en su Tesoro de la lengua castellana (I6II): "Clamor algunas veces significa el toque de la campana o campanas, quando tañen a finados, que llaman clamorear». Lo mismo podrá decirse de otros términos usados en la traducción como "tumbar» (desde el principio aparece por doquier) o "potenza» (Genet, 223:6), o «relieves» (Hegel, 259i:I8; Hegel, 263:19). Glas es un clamor transtemporal.

Fabio Vélez Bertomeu: Analía, muy elogiosamente, ha puesto de relieve algo que en estos tiempos suele por lo general pasar de manera discreta, si no es que flagrantemente desapercibida, a saber, la edición y, más en concreto, el cuidado de la misma. Creo que, en este sentido, y al igual que ya se ha hecho con los traductores, habría que tener un especial recuerdo con Joaquín Gallego. Así lo creo, y así lo defenderé. Joaquín pertenece a una clase de editores, en evidente peligro de extinción, que opera en el gremio como era costumbre hace siglos, es decir, considerándolo como un oficio propio de artesanos. Prueba de ello es no sólo la asunción de una empresa como esta, sino, y más si cabe, su labor como maquetador. Recuerdo encontrarle en su casa (un día de verano del 2015), parapetado de libros de arte y edición, frente a dos pantallas gigantescas de ordenador, y saboreando una reciente conquista de maquetación (que, si mi memoria no me traiciona, tenía que ver con la portada). Aquel gesto de satisfacción en su rostro evoca, y mucho, a los que teníamos en las sesiones de traducción cada vez que dábamos con un hallazgo feliz para una palabra aparentemente intraducible. Así pues, si Analía hablaba de una traducción im-posible, no estaría de más, creo, referirnos a la maquetación como una maquetación también im-posible. Para terminar, y por seguir con la anécdota, si Delmiro fantaseaba - y con fundadas razones teóricas - en una edición libre, yo fantaseé desde el primer día con encontrar un editor como Joaquín Gallego. Creo que era Flaubert quien decía que cada libro elije a sus lectores; pues bien, podríamos afirmar, mutatis mutandis, que cada libro elije a su editor. Y para prueba, este botón.

D.R.: ¿Cómo no traducir Glas? ¿Cómo no confundir título y obra? Y especialmente en esta traducción, pues en ella se intenta no dejar palabras en francés en el texto, es decir, se intenta, precisamente, traducir. Esa es la dificultad y también el reto. Bien es sabido que para Derrida la traducción es, a un tiempo, imposible y necesaria. No traducir Glas sería como abandonarlo todo a la noche de la intraducibilidad, a lo misterioso e inescrutable. Sería aceptar lo imposible sin asumir la necesidad. No obstante, traducirlo completamente, sin mácula, sin rastro, sin resto, sería renunciar por completo al secreto de la noche. Sería asumir la mera necesidad sin aceptar lo imposible. La noche y el día como dos metafísicas opuestas que sin embargo sólo sumarían uno, un uno total, completo, sin resto en la operación. Quizá Glas sea la mejor prueba de esa imposible necesidad. Ciertamente, Glas necesita ser traducido para su difusión, desde un punto de vista pedagógico, pero también para su lectura, no solamente en español sino 
también en francés, y en tantas otras lenguas. La traducción no sólo alimenta la supuesta lengua de recepción. Siempre hay más de una lengua. Y creo que Glas no es únicamente un reto para la traducción, debido a su extrema dificultad; creo que no solo Glas necesita de la traducción para ser «leído» sino que la traducción necesita de Glas para que esta pueda leerse a sí misma, comprender su límite, es decir, a un tiempo su propia necesidad e imposibilidad.

A.G.: En la entrevista que les hice hace algunos años, Cristina mencionaba que «si, como profesora, quieres dar a conocer a un pensador como Derrida en España, donde cada vez los jóvenes, los estudiantes, saben menos francés (hace tiempo que todos aprenden inglés en el colegio y en el instituto, pero muy pocos aprenden francés), hay que traducirlo». Este deseo de lectura de la desconstrucción (me anticipo y les pido disculpas por este uso del término sobre el que cabría reponer algunas discusiones que habilitarían otra entrevista), o más bien, este deseo de contagiar el deseo de lectura de la desconstrucción unida a la traducción, se advierte desde el mismo nombre del seminario que Cristina coordina desde los años noventa: Decontra. Pero se vislumbra también en esta preocupación por difundir en español no sólo las puntillosas referencias bibliográficas que en su versión al inglés reponen John Leavy y Richard Rand en GLASsary sino además por completar esta información con las traducciones al español más el detalle de las líneas en que aparecen esas citas (un trabajo a cargo de María José Abella Maeso para la columna de Hegel y de Julián Santos Guerrero para la columna de Genet con la colaboración de Concepción Torralba Mateo y de Juana Isabel López Bernal: prueba del descomunal trabajo realizado por el equipo involucrado en esta tarea meticulosa). Pero además, por si esto fuera poco, sea agrega esa suerte de cuaderno de notas con la reposición de los términos franceses, la traducción realizada y la página en que estos términos aparecen tanto en francés como en español. Recuerdo que en la conversación anterior habían pensado en hacer con estas notas un $\mathrm{CD}$. Luego optaron por esta resolución que evalúo más ágil en término de lectura y más potente en términos de archivo considerando la doble exigencia derrideana para todo archivo, es decir, que esté ubicado en un sitio accesible y en un soporte resistente. ¿Qué fantasías de intervención tienen respecto de ese trabajo didáctico que se han tomado? ¿Qué esperan que se haga con esta producción, más allá de la increíble accesibilidad a/de Derrida que ustedes promueven, no sólo con su traducción sino también con la cuantiosa producción de divulgación en la que se empeñan?

C.P.: ¿Cuando hablas de fantasías a qué te refieres? ¿A esa frase de consuelo o de ánimo que asegura que «de ilusión también se vive»? Ahora ya fuera de bromas: como ya te comenté en la entrevista que nos hiciste en 2008 y como tú muy bien recuerdas también aquí, considero - y aquí, por supuesto, hablo únicamente a título personal — que a aquellos a los que el pensamiento de Derrida nous tient à coeur, a los que nos parece imprescindible su obra, tenemos que asumir la respon- 
sabilidad de traducirlo para dar a conocer sus textos y, así, su pensamiento a los lectores hispanohablantes y, más concretamente, a los estudiantes jóvenes, cada vez más numerosos desgraciadamente, que no saben francés.

Pienso que, gracias a que muchos hemos contraído esa responsabilidad, hoy por hoy ya hay un número considerable de textos de Derrida traducidos al espańol (en buena medida, por cierto, debido a la labor de las editoriales sudamericanas y, más concretamente, de las argentinas) pero, aun así, todavía quedan muchos libros suyos muy importantes por traducir. Y, hasta ahora, el reto sin duda más apremiante y más difícil era Glas. Me permito de nuevo aprovechar la ocasión para dejar constancia aquí, una vez más también, de mi infinito agradecimiento a todo el equipo de La Oficina de Arte y Ediciones y, muy especialmente, al profesor Arturo Leyte por haberse atrevido — como tú dices- a asumir el reto de publicar la traducción española de Clamor. Han sido muchas las editoriales con las que hemos contactado durante todos estos ańos y ninguna de ellas, salvo la suya, quiso arriesgarse en semejante empresa.

Pero, volviendo a tus preguntas, te repito de nuevo que, tanto a nivel docente como incluso a nivel personal, vital, lo que a mí más me interesa es el pensamiento de Derrida y, por consiguiente, una de mis mayores alegrías y satisfacciones es cuando logro transmitir ese interés y ese entusiasmo por Derrida a los estudiantes. Por eso lo doy a conocer siempre que puedo en mi trabajo docente, y por eso escribo sobre él y lo traduzco.

¿Fantasías de intervención respecto al «trabajo didáctico» que hemos hecho con motivo de la traducción al español de Glas? Pues no sabría decirte nada nuevo ni nada específico. Considero que este «trabajo didáctico» se inscribe en la misma línea que todas las demás traducciones, cursos, seminarios, libros, artículos, etc., que algunos de nosotros llevamos haciendo desde hace más o menos tiempo y con mayor o menor intensidad en función de la edad, de las oportunidades y del grado de implicación de cada uno con el pensamiento de Derrida.

Dicho esto, no cabe duda que Clamor ha merecido un trato especial por nuestra parte: con esas referencias bibliográficas y con esa lista de «Términos franceses con traducción motivada al español en Clamor (Glas) de Jacques Derrida», que — como tú bien señalas — pueden consultarse en internet, en la página web del Grupo Decontra. Pero esto se debe a unos motivos muy concretos. Por una parte, en lo que se refiere a las referencias bibliográficas, como bien sabes, Glas es el único libro en el que Derrida no consigna las fuentes de las numerosísimas citas que hace a lo largo de las dos columnas, debido — no me cabe ninguna duda - a esa distribución tipográfica tan especial de Glas. Puesto que los traductores norteamericanos de Glas se tomaron, en 1986, el inmenso trabajo de rastrear todas esas referencias y de ponerlas a disposición de los lectores seńalando tanto la versión, normalmente original, citada por Derrida como su traducción inglesa, cuando la había, a nosotros nos pareció casi un delito no aprovechar ese trabajo tan importante que ya estaba hecho. El equipo de nuestro proyecto encargado de ese trabajo pudo así conservar todas las referencias de los «originales» limitándose 
- es una forma de hablar, porque la tarea que hicieron no deja de ser enorme y laboriosa- a buscar las referencias de las traducciones españolas cuando las había. El hecho de ofrecer a los lectores las referencias de las traducciones españolas (una vez más, cuando las hay), junto con las versiones «originales» que cita Derrida en todos sus escritos (a excepción de Glas), es algo que siempre hemos hecho en nuestras traducciones (me refiero, al menos, a las que yo he hecho, sola o en colaboración). Pero, en el caso de Clamor, de no haber dispuesto de ese tremendo trabajo previo que hizo John P. Leavy (traductor junto con Richard Rand de Glas al inglés) no creo que nos hubiésemos atrevido a acometer una labor tan descomunal que implicaba localizar, antes que nada, una por una todas esas innumerables referencias originales de las citas.

Por otra parte, la lista de términos franceses y de sus traducciones al español es algo que, en cambio, nunca habíamos hecho en otros libros traducidos. Si acaso, para determinadas palabras, hemos puesto alguna nota de traducción a pie de página. Pero, tratándose de Clamor, no sólo esto nos parecería improcedente debido, una vez más, a la disposición tipográfica del texto que, si Derrida no quiso desbaratar con notas al pie, no íbamos a ser nosotros los que lo hiciésemos, sino también porque las notas de traducción hubieran tenido que ser casi continuas y porque, aunque normalmente hemos intentado conservar siempre, a lo largo de las columnas, la misma traducción para cada término, a veces esto no ha sido posible. Con esta lista, que indica la situación de cada término y de su traducción en el lugar exacto tanto del texto francés como de la traducción española, damos la posibilidad a los lectores de hacer por sí mismos todas las contrastaciones terminológicas que consideren oportunas.

Volviendo de nuevo al «trabajo didáctico» al que aludes, lo que sí que me resulta muy satisfactorio es comprobar que, a pesar de que las instituciones académicas españolas en general y la mayoría de sus docentes en particular siguen mostrando todavía un enorme desconocimiento y una no menos inmensa reticencia — que también podríamos denominar inquietud, alarma o miedo- en lo que concierne al pensamiento de Derrida, el panorama de su recepción en España se torna, a mi modo de ver, bastante más esperanzador al constatar que los jóvenes, estudiantes, licenciados, doctorandos y doctores, se interesan cada vez más por su labor.

De nuevo, me he alargado excesivamente en mis respuestas pero no puedo por menos que hacer, antes de terminar ésta, un pequeño comentario que no tiene sin embargo nada que ver con lo que tú has preguntado ni con lo que yo te he contestado. Y que espero que no te lo tomes a mal porque lo hago desde la amistad hacia ambos (ahora entenderás por qué digo «hacia ambos»). Hablas — te cito literalmente- de «este deseo de lectura de la desconstrucción (me anticipo y le pido disculpas por este uso del término sobre el que cabría reponer algunas discusiones que habilitarían otra entrevista), o más bien, este deseo de contagiar el deseo de lectura de la desconstrucción unida a la traducción, se advierte desde el mismo nombre del seminario que usted coordina desde los ańos noventa: 
Decontra». A mí no me molesta en absoluto el uso del término «deconstrucción» siempre y cuando no se utilice - como ocurre en tantas ocasiones - sin saber de lo que se está hablando, lo cual no es tu caso. Lo que sí me ha extrañado es que, hasta ahora, no me había dado cuenta (y eso que nos hemos visto varias veces en persona) de que utilizas el término "desconstrucción» (con s) en lugar de «deconstrucción» (sin s). Hace ańos, Patricio Peñalver y yo mantuvimos durante un tiempo esa pequeña polémica lingüística y nunca conseguimos ponernos de acuerdo. Así que en la actualidad, en España, cada cual emplea el término como más le gusta aunque, normalmente, salvo Patricio y sus más allegados, se suele utilizar mucho más el término "deconstrucción" que el término con esa "S», a mi entender, tan incómoda de pronunciar. En todo caso, la Real Academia de la lengua española admitió, en la 22da edición (200I) de su diccionario, el término «deconstrucción». Sin embargo, el término «desconstrucción» (con s) sólo aparece mencionado y con la siguiente salvedad: «la palabra desconstrucción no está registrada en el diccionario. La que se muestra a continuación tiene formas con una escritura cercana». Naturalmente dicha palabra no es otra que "deconstrucción». Me resulta divertido pensar, visto lo visto, que tú eres un poco «la Patricio Peñalver argentina» porque - lo he estado comprobando (es un asunto con el que me siento muy concernida aunque hayamos dejado ya atrás toda esa polémica. Ahora ya tan sólo siento cierta curiosidad y me hace cierta gracia cuando surge la cuestión) en el libro Derrida político dirigido por Ana Paula Penchaszadeh y Emmanuel Biset - tanto ellos como, por ejemplo, Mónica Cragnolini o Gabriela Balcarce utilizan «deconstrucción» (sin s). Por cierto, tú misma así lo señalas, ¡nuestro grupo de trabajo sobre Derrida se llama «Decontra», no «Descontra»!

L.F.C.: En una obra como Glas dedicada a Hegel y a Genet, tejida con mil citas, explícitas o implícitas, merecía la pena ofrecerle al lector y sobre todo al estudioso de Derrida, las referencias de las mismas en las versiones españolas de los autores citados. Sin la labor previa, descomunal sin duda, de John Leavy en el GLASsary no hubiera sido posible llevarla a cabo con nuestros medios. Dicho esto, la búsqueda de las referencias en las traducciones españolas ha sido un trabajo inmenso, de mucho esfuerzo y a veces gran dificultad que Julián y María José con la ayuda de Concha y de Juanabel llevaron a buen término con gran perfección y minuciosidad. Por otro lado, la reposición de términos franceses que han sido traducidos de forma singular, creativa en muchos casos, se hacía también absolutamente necesaria para quien tenga interés por ahondar en el texto, en su sentido, en su comprensión. ¿Fantasías didácticas? Desde mi punto de vista, sólo queremos presentar un instrumento de ayuda que pueda estar en manos de todo el mundo. Lo veíamos simplemente como exigencia de un trabajo bien hecho.

F.V.B.: Me gustaría dimensionar una apreciación de Analía que, en la cascada de sugerencias e ideas geniales de su pregunta, podría quedar en un segundo plano. Me refiero, pues, a la labor de divulgación que, por medio de la traducción, ha 
jugado Cristina (pero también, indudablemente, Paco y Patricio) a este respecto. Contaré esta breve anécdota personal. ¿Cómo llegué yo a Decontra, puesto que no tenía contacto ninguno con la UNED? Muy sencillo: fascinado en la carrera por la obra de Derrida (primero, en traducción), advertí que la mayoría de las traducciones venían firmadas por los antes referidos. Fue así como entré en contacto con ellos, y con su hospitalidad. Derrida, quizá exagere las cifras (pues hago un cálculo intuitivo), ha sido leído en traducción por el 80-90 \% del público en Espańa y Latinoamérica. Visto así, desde esta abrumadora perspectiva, la traducción cobra una visibilidad esencial para la divulgación de una obra escrita en una lengua extranjera. Si es que es posible, me gustaría preguntar a Cristina si cuando ella empezó a traducir a Derrida tomó conciencia de la responsabilidad — no sólo lingüística- que asumía al ejercer de mediadora y divulgadora.

C.P.: Si me lo permites, Analía, voy a tratar de responder a esta pregunta de Fabio. Para ello, creo que es importante señalar que las primeras traducciones que hice de Derrida fueron relativamente tardías pues datan de 1989 (puede parecer un poco ridículo, en 20I6, hablar de «traducciones relativamente tardías» refiriéndome a 1989, una fecha que, hoy en día, a muchos les debe de sonar a "prehistoria» pero, si se tiene en cuenta que Derrida publicó su primer texto en 1962, creo que el adjetivo "tardío» resulta bastante pertinente) y consistieron básicamente en la traducción de una serie de textos suyos más o menos dispersos: por un lado, una entrevista que él mismo me concedió en torno a las afinidades y diferencias entre deconstrucción y feminismo (entrevista que se publicó en el número 3 [1989] de la revista Politica y Sociedad de la Facultad de Ciencias Políticas y Sociología de la Universidad Complutense de Madrid), por otro lado, siete textos extraídos de distintos libros y revistas para el número I3 (1989) de los «Suplementos» de la revista Anthropos (traducciones reeditadas en Cómo no hablar. $Y$ otros textos y El tiempo de una tesis. Barcelona, Proyecto A Ediciones, 1997) y, finalmente, otros dos textos: «¿Qué es la poesía?» y, en colaboración con Patricio Peñalver, “Ich bünn all hier. Ya estoy aquî". Conversación con Jacques Derrida. Entrevista de Maurizio Ferraris» en torno al texto anterior (para el número 9/Io — $1989 / 1990$ - de $E R$, la ya desaparecida y memorable revista de Filosofía de la Universidad de Sevilla).

Durante el curso académico I99I-I992, tradujimos en grupo, con motivo de un curso de doctorado de la UNED sobre "Deconstrucción y traducción», el $2^{\circ}$ Apartado de Du droit à la philosophie. La editorial Paidós publicó esta traducción, con el título El lenguaje y las instituciones filosóficas, en I995, año precisamente en el que ya empecé a traducir libros de Derrida y a hacerlo con cierta continuidad.

Señalo estos comienzos, como he dicho, para responder a la pregunta de Fabio acerca de si, cuando comencé a traducir a Derrida, era consciente de «la responsabilidad — no sólo lingüística - que asumía al ejercer de mediadora y divulgadora». Sinceramente, creo que no. Por descontado que ya entonces me interesaba que los estudiantes, que no supieran francés, pudieran leer a Derrida 
en español pero pienso que esa labor de traducción de sus textos como una responsabilidad incuestionable que hace ya años asumo a nivel no sólo docente sino también personal es una decisión que se fue gestando sin duda poco a poco y de una manera casi imperceptible. Lo cual no tiene por qué extrañarnos si, como dice Derrida, «la decisión responsable debe ser esa im-posible posibilidad de una decisión "pasiva”, una decisión del otro en mí que no me exonera de libertad ni de responsabilidad alguna».

Cristina Rodríguez Marciel: Aprovecho mi primera intervención en esta tercera pregunta para saludarte muy afectuosamente, Analía, puesto que no he tenido ocasión de volver a verte personalmente desde tu estadía de investigación en la UNED en 2008. Este saludo se hace extensivo a este nuevo proyecto auspiciado por la Universidad Nacional del Litoral y materializado en forma de una espléndida revista digital, El taco en la brea, cuya dirección tienes entre manos. Y creo adecuado comenzar mi intervención en esta tercera pregunta y limitarla, además, a esta única respuesta, en primer lugar, porque las intervenciones de los coordinadores de Clamor son muy oportunas, explícitas y exhaustivas y abundar más en lo ya dicho, además de innecesario, sería correr el riesgo de volver prolijo lo que ambos han expuesto con gran acuidad y de manera cabal y, en segundo lugar, porque desde aquí siempre puedo recuperar, de manera brevísima, como es mi intención, algunos aspectos de tus cuestiones en los que poder demorarnos todavía unos instantes. He querido enlazar en este punto porque me ha parecido muy significativa, e incluso chocante puesto que se trata de una cuestión «idiomática», la expresión que has empleado para preguntarnos por "nuestras fantasías de intervención didáctica» con respecto a Clamor. Ha sido, por tu parte, una deliciosa manera de poner en evidencia que la lengua española es por sí misma «más de una lengua», como por lo demás lo es cualquier lengua, tal y como Derrida no dejó nunca de recordárnoslo. Pero, quizás, en español, el sintagma «más de una lengua» adquiere mayor alcance o pertinencia cuando se empieza a oír hablar de manera reiterada de «las» lenguas españolas poscoloniales. Me parece que el español de España, que también es a su vez una multitud de lenguas españolas, hace tiempo que adjuró de palabras como «fantasía» o «ilusión» por lo que connotan de irrealidad o ensońación. Hablaríamos entonces quizás de «expectativas». En este punto, además de suscribir todo lo que ha expuesto Cristina de Peretti, y que siempre es extensible, como ella misma ha seńalado, a cualquier texto de Derrida que traducimos o que enseñamos para tratar de divulgar su pensamiento, creo que no albergamos ni en los inicios ni ahora ninguna «expectativa» concreta de intervención con respecto a este libro en particular. Sin embargo, Clamor se ha empeñado en demostrar hasta qué punto, tanto en los aspectos didácticos como en los divulgativos, y cualesquiera que hubieran podido ser nuestras expectativas y previsiones con respecto a la traducción, fuimos incapaces de prever en absoluto algunas de las intervenciones que de hecho se iban a producir y que, además, iban a revelarse, de manera sorprendente, extraordinariamente fecundas. Me refiero 
en concreto al trabajo que un arquitecto, Vicente Medina Gómez, compañero reciente del grupo Decontra, ha llevado a cabo con lo que ha llamado «Parque Glas", con el que se ha convertido en un magnifico embajador de Clamor, y que se ha materializado en una exposición itinerante que ya ha visitado varios países, empeñándose en demostrar que Glas o Clamor es, en muchos aspectos, «más de un libro» y «más que un libro», puesto que ha hecho de él una propuesta pictórica y arquitectural. Vicente Medina entró en nuestras vidas cuando ya no había reuniones de traducción (aunque el trabajo seguía en manos de los coordinadores, como ya te han comentado, en vías de acometer una y otra vez la enésima «revisión» con miras a ultimar los detalles más nimios) y estoy convencida de que fue su inicial contacto con ese libro en concreto y con su «arquitectura» lo que hizo que, precisamente, un arquitecto quedara inmediata e irremisiblemente prendado de esa "producción». Y la «arquitectura» de Glas, como bien sabes, no es una cuestión baladí, sino una cuestión teórica de primera magnitud con la que desestabilizar la autoridad de la metáfora «arquitectónica» con la que se han constituido todos nuestros sistemas de pensamiento. En este caso, y a partir de Glas/Clamor, hemos asistido a aquello que decía Aristóteles en Metafísica, esto es, que "los que enseñan creen haber alcanzado el fin cuando han mostrado al alumno enseñando». Como ves, efectivamente, y tú misma lo has dicho, hay un «más allá» de la accesibilidad que tratamos de promover, pero que escapa a cualquier previsión y nos sorprende en sentidos que no podíamos esperar ni en nuestras más salvajes fantasías ni en nuestras más realistas previsiones. «Derivas» como la de Vicente Medina no sustituyen en absoluto, obviamente, el ingente trabajo de traducción acometido por el equipo, pero lo complementa traduciéndolo a su vez a otra lengua, enseñándolo (y no sólo en el sentido de instruir, sino en el de mostrar, exponer y exhibir), divulgándolo y dándole una vida diferente. En el mismo sentido quiero abundar en tu propuesta inicial cuando has descrito con minucioso detalle la tapa del libro diseñada por Joaquín Gallego para La Oficina de Arte y Ediciones. No sólo tenemos que agradecerles haber querido emprender la arriesgada tarea de publicar un libro cuya producción, por sus especiales características formales, resultaba excesivamente costosa para cualquier editorial, sino que no hayan escatimado esfuerzos en ninguno de los aspectos que han afectado a todo el proceso de producción hasta que Clamor llegó a las librerías. Esa deslumbrante portada (ciertamente, has elegido muy bien el término "deslumbrante» y estoy por completo de acuerdo con ese calificativo) desbordó también todas nuestras expectativas porque, por ańadidura, y como un «don» no esperado, ha hecho del «objeto-libro» Clamor (además de la portada puede decirse lo mismo de cualquiera de los detalles de su elaboración: desde la calidad del papel hasta la bellísima impresión tipográfica) una forma visual poderosamente "pregnante» en el sentido en que esa categoría estética se aplica a las obras de arte que tienen la capacidad de atraer la atención del observador. Ya he empezado a acostumbrarme, pero los primeros días me resultaba muy difícil poder mirar el libro de manera distraída retirando inmediatamente la mirada, siempre me quedaba atrapada en él mirándolo un ratito más... 
Por supuesto, tienes razón cuando afirmas que en la portada se ha hecho el doble juego de "más de una lengua», pero me aventuraría a decir que ese juego es más múltiple que doble, porque, como no podía ser menos puesto que se trata precisamente de "desbordamiento de la lengua», no sólo están ahí la lengua francesa y la española, está la lengua del diseño gráfico y la de la geometría donde hablan las líneas paralelas y las que están en intersección, perpendiculares u oblicuas. $\mathrm{O}$ los círculos que no se cierran porque siempre se encuentran intersticios por donde la línea que los dibuja se excede. Si me apuras, está la lengua de los colores, que tú misma has resaltado con extraordinaria receptividad pero sin explicitarlo: ¿qué colores podría tener Clamor sino negro, rojo y blanco; la muerte, el amor, la vida...?

D.R.: Yo creo que Clamor, el trabajo de su traducción, es ya una inmensa labor didáctica. En primer lugar, para los traductores, pues no sólo se trata de que uno aprende, y mucho, cuando traduce semejante obra, sino que uno aprende a aprender; uno se ve en la necesidad de elaborar un nuevo sentido de la didáctica, una nueva configuración del enseñar y del aprender, del dar y del recibir, que obliga a convulsionar las estructuras heredadas de la transmisión vertical del conocimiento. Este hecho, en segundo lugar, obliga a la profesora, o al profesor, y no olvidemos que todos los miembros del equipo de traducción se mueven, más o menos, en el mundo de la enseńanza y de la investigación, a reformular las reglas de su ejercicio docente, a pensarlas al menos, si tiene intención de «enseńar» Clamor. ¿Cómo se enseña un clamor? Quizá, precisamente, la fantasía sea fundamental en este sentido, pero no porque estemos hablando de algo alejado de la realidad, sino porque lo fantasmático y lo fantológico están muy presentes en esta obra. Se podría haber titulado "toque a fantasma» (risas). Aquello que vuelve, que amenaza con volver, y asedia la tranquilidad de lo real, de la academia, si quieres, con sus didácticas pretendidamente alejadas de la fantasía, es precisamente ese fantasma. Se quiera o no, el fantasma hará su aparición. Pero también es cierto que si los lugares tradicionales para la didáctica cierran sus puertas a aquello que viene, si se conservan conservadores, por así decirlo, y toda institución es conservadora por definición, no significará en ningún caso la contención de lo que viene, sino la creación de nuevos lugares más amables a semejante venida. En este sentido, la institución académica quizá está dejando de ser el lugar privilegiado de los saberes, de ciertos saberes al menos, de cierto modo de saber, a pesar de que sin duda resistirá todavía mucho tiempo a otras formas de didáctica.

A.G.: En esta misma dirección Web donde aparecen estos archivos con las referencias bibliográficas y con las aclaraciones de términos se inserta otro con la condensada lectura que repiten en la solapa del libro. Hay allí dos hipótesis fuertes. En la enunciación de la primera se juega a su vez la reposición del primer sentido más literal pensado hace ya treinta años para la traducción del título: «Glas ["toque de muerto"'], traducido al español como Clamor, constituye un máximo exponente de lo que Jacques Derrida denomina en De la gramatología "El fin del libro y el 
comienzo de la escritura”». Esta hipótesis se justifica a partir de la arquitectónica del texto cuyas columnas, atravesadas a su vez por múltiples injertos y envíos, vuelven sobre la literalidad del polémico término en cuestión: «las campanas del título doblan a muerto por la linealidad de la lectura, por la forma ideal del Libro como saber absoluto, así como por la identidad del nombre propio y de la firma [y] del autor, supuesto poseedor y garante último del sentido de un texto». Esta actuación derrideana de sus propias teorías es lo que pareciera intentan poner de relieve en esta solapa junto a la otra hipótesis: la que sostiene que «la obra de Derrida también pretende "tocar a glas", esto es, pronunciar una sentencia de muerte para la filosofía en su conjunto o, por lo menos, por el modo de hacer filosofía» vigente hasta entonces mientras explota los sentidos del «resto». Sobre la actualidad de estos problemas en el campo de la teoría literaria vuelvo en la reseña de esta traducción descomunal que han hecho y que se publica en esta misma revista. En esa línea, considero valioso conocer la visión que ustedes tienen respecto de esta escritura del 74 y su actualidad para el campo de la filosofía: ¿̧hasta qué punto las cuestiones que Derrida «solicita» (y uso deliberadamente esta palabra intentando acercarme al sentido que el término cobra en sus textos) siguen vivas en la filosofía hoy?

C.P.: Antes de contestar a tu pregunta, me gustaría hacer unas serie de observaciones previas. Es cierto que, durante un tiempo, Derrida utilizó términos como «fin» y como «clausura» insistiendo continuamente en que la clausura no es el fin. Cuando, por ejemplo, habla de la «clausura» de esa «metafísica occidental» o «metafísica de la presencia» (de claras reminiscencias heideggerianas) que, como especifica tantas y tantas veces, jamás ha concebido - pese a las malas y mal intencionadas interpretaciones de algunos — como una totalidad homogénea e idéntica a sí misma sino, muy por el contrario, como un proceso histórico variable, internamente recorrido por múltiples diferencias y rupturas a pesar de esa «estructura dominante» que lo atraviesa y que Derrida bautiza con los nombres de «logofonocentrismo» o de "falogocentrismo», pues bien, cuando habla de la «clausura» de esa metafísica, Derrida no se refiere en absoluto a un posible fin de la misma ni a que ésta se encuentre confinada dentro de una especie de simple círculo lineal cerrado, sino a una suerte de agotamiento que no implica de ningún modo un adentro y un afuera respecto a dicha metafísica. Ahora bien, cuando Derrida habla del «fin», por ejemplo, «del fin del libro y del comienzo de la escritura», tampoco se está refiriendo a que la época del libro (y, con ella, la del logofonocentrismo, la del humanismo, etc.) ha muerto y comienza entonces una nueva época que sería la de la escritura y la de esa supuesta "posmetafísica» de la que algunos hablan. En primer lugar, porque la escritura (o archi-escritura) — tal y como la concibe Derrida - es la condición misma de posibilidad del lenguaje en general y, en segundo lugar, porque Derrida siempre ha asegurado que «la» metafísica no es algo que se pueda superar sin más ni de una vez por todas. No hay que olvidar que la deconstrucción, que parte de la exigencia de una complejidad y, por consiguiente también, de una divisibilidad sin límite, —Derrida lo afirma con frecuencia— no 
se da jamás por concluida. Para terminar con estas observaciones, recordar finalmente, que los términos de "clausura», «fin» y "metafísica de la presencia» son términos que, tras utilizarlos pedagógica y estratégicamente durante un tiempo, Derrida deja de emplear cuando ya no los considera oportunos (cfr., por ejemplo, la entrevista que en 1991 le hace Dominique Janicaud y que está publicada en $\mathrm{Hei}$ degger en France. París, Hachette/Albin Michel, 200I, Tome 2, IOI-IO2).

Dicho esto, voy a tratar de contestar lo mejor que pueda - y también lo más brevemente posible - a tu pregunta de que "hasta qué punto las cuestiones que Derrida "solicita" (...) siguen vivas en la filosofía hoy». Personalmente, no me cabe la menor duda de que esa estructura «logofonocéntrica» y «falogocéntrica» que representan tantos de los conceptos que Derrida «solicita» en Clamor y en todos sus demás textos, sigue imperante, hoy en día, en la filosofía pero también, sin ir más lejos, en el mundo mismo que nos rodea. El logofonocentrismo persiste, aunque en ocasiones más o menos distorsionado y desfigurado. Como he apuntado antes, su clausura — si es que la hay — no es su fin. Todas las mutaciones más o menos inauditas que, un día tras otro, vemos producirse a nuestro alrededor de una manera vertiginosa dan constantemente lugar, a todos los niveles, a configuraciones novedosas de todo tipo que, no obstante, siguen atrapadas de una u otra forma en esa dislocación del logocentrismo que en ocasiones también tratan de reflejar. Tal es el caso, por ejemplo, de las nuevas tele-tecnologías que — pese a sus muchas e indudables utilidades - no cejan, sin embargo, en seguir fabricando, y reforzando así, esa sempiterna creencia, certeza o verdad (meras impresiones, por descontado, más ilusorias y espectrales que efectivas y reales) en y de la primacía y autoridad de un flamante y siempre dudoso presente "en vivo» y «en directo», que no deja de ser un mero trasunto de ese ya presuntamente trasnochado pero indefectible presente metafísico.

L.F.C.: Me viene a la mente como respuesta a su pregunta una ocurrencia. Por las tierras de antiguo reino de León, Asturias y Galicia, en el noroeste de España, se utiliza un vocablo singular para «tocar a muerto», el vocablo «encordar». Encordar, en su uso general, significa poner cuerdas a un instrumento de música, y tiene su raíz etimológica en el vocablo latino chorda, -ae (cuerda de un instrumento musical); pero tengo para mí que el vocablo «encordar» con el significado de «tocar a muerto» tiene otra etimología: al igual que recordar, parece tener su raíz latina en cor, cordis (corazón). Bien sabido es que en la cultura antigua la sede de la memoria estaba en el corazón (reminiscencias las tenemos en la expresión inglesa learn by heart, o el par coeur en el francés). Encordar sería, pues, un traer al corazón, al interior de la memoria, el acontecimiento de una muerte, la presencia de un muerto, de unos restos. Podíamos entender Glas como la expresión de una gran liturgia de «solicitación», en la que se celebra, encordando, el fin sin fin de algo de lo que no podemos desprendernos: ¡el libro?, ¿el sujeto?, ¡el autor?, ¡el género?, ¿el nombre propio?, ¿el apellido familiar?, ¿nuestra herencia?, ¿nuestra herencia griega?, ¿nuestra herencia hebraica? Fin sin fin, sin duda. Doble colum- 
na: dialéctica y galáctica, memoria y antimemoria, tumba llena dionisíaca, tumba vacía crística. ¿Muerte de la filosofía? En absoluto. ¿Muerte de la literatura? De ningún modo. El escritor, como el campanero, encuerdan en el entre tocando a glas: entre las dos campanas que clamorean en la espadaña, entre las dos columnas que encuerdan solicitando el cuerpo glorioso de los restos. Otra forma de $\mathrm{p}(\mathrm{r})$ ensar, otra forma de escribir. Glas es un memorial, una acción litúrgica; pero también una premonición, una profecía. El clamor para una filosofía del futuro.

F.V.B.: Sin ánimo de resultar oscuro, me gustaría invitar al lector a comparar el arranque de Clamor con el primer capítulo de la Fenomenología del espiritu de Hegel. Yo hablaría, más bien, de una muerte; en efecto, una suerte de canto fúnebre, elegíaco incluso, acerca de una manera de hacer filosofía. Blanchot dice en alguna parte «quand je parle, la mort parle en moi». Pues bien, creo que una asunción como esta acompaña a Derrida en todas sus empresas. Recuerdo que la primera vez que lo advertí, y que resultó para mí toda una revelación, fue en Espectros de Marx. Pero sin duda alguna, aflora como un torrente por doquier en Clamor. Si tuviera que cifrarlo de alguna manera, diría algo parecido a esto: hacer filosofía es hacer el duelo. Pocas filosofías han encarado de frente este problema. Es más, podría decirse que la filosofía en general ha intentado si no reprimir, sortear este problema.

D.R.: Tu pregunta me hace recordar una reseña sobre Glas que se publicó en un conocido periódico de nuestro país, una reseña no muy amable que digamos, que, a pesar de alagar tanto la traducción como la edición, dice que es un «bello objeto arqueológico» pero que su «frescura nos resulta ajada», son palabras del autor de la reseña, como si de alguna manera llegase demasiado tarde, como que ya no toca. Evidentemente, el autor de la reseńa está pensando en determinadas características formales relativas a la composición y descomposición del texto que a principios de los años setenta del pasado siglo, y sin ordenador, Derrida pone en marcha. El propio Derrida reconoció que con un ordenador probablemente no hubiese escrito Glas, al menos no de esa forma. Con todo, me resulta difícil pensar que la problemática formal que pone en juego Clamor esté superada hoy, especialmente por la computación — para Derrida la tecnología decuplica el poder de los fantasmas_- y del contenido ya ni hablamos, especialmente en esta obra donde la frontera forma/contenido queda en entredicho desde su no inicio hasta su no final. Por supuesto, no me corresponde a mí decir si Clamor es, o no, el actual adalid de la actualidad, con todo lo que supone para Derrida la necesaria imposibilidad de pensar la actualidad, pero sí me gustaría relacionar esta problemática de la actualidad con cierto don de la traducción, pues de alguna manera la traducción es siempre contemporánea, siempre coetánea, al texto independientemente de lo que traduzca. Y para rebatir, un tanto artificiosamente quizá, ese posible «retraso» de Clamor, simplemente decir que desde Estados Unidos de América se está preparando una nueva traducción de Glas al inglés, a cargo de Geoffrey Bennington y David Wills, nada menos. Por lo tanto, Clamor 
aparece mucho después que el Glas inglés, ciertamente, pero también antes, y estas apariciones, la que aquí nos tiene y la que está por venir, parecen indicar que Glas parece mucho más actual de lo que parece. Vamos, que hay Glas para rato.

A.G.: Casi finalizando, quisiera que pudieran precisar al menos una dificultad concreta en el trabajo de traducción que recuerdan especialmente volviendo sobre la idea abrigada por Derrida de que en verdad los desafíos más importantes para el traductor se plantean justo cuando un acontecimiento en la lengua vuelve la tarea im-posible.

C.P.: Como ya he apuntado en cierto modo en alguna de mis respuestas anteriores, si hiciésemos una lista de las dificultades con las que nos hemos ido encontrado a lo largo de la traducción, aquélla sería interminable. La mayor parte de esas dificultades las reseñamos en ese apéndice «virtual» a Clamor que hemos denominado «Términos franceses con traducción motivada al español en Clamor (Glas) de Jacques Derrida» y del que ya hemos hablado anteriormente.

Dicho esto, hemos topado con problemas casi a cada paso, casi en cada línea. Los lectores de Derrida estamos acostumbrados a esa escritura suya tan creativa y tan ingeniosa que, a pesar de estar tan apegada a la lengua francesa, sabe no obstante violentarla a la perfección, incluso cuando utiliza el lenguaje más sencillo y popular, y que, mediante un minucioso y riguroso trabajo a nivel tanto semántico-sintáctico como fónico y gráfico, sabe deslizar, en cada frase, otras tantas derivas que desencadenan una pluralidad de nuevas frases y de nuevos sentidos imprevisibles, provocando así unos efectos que se resisten a la simple transposición de un sentido de una lengua a otra. Pero, si todos los textos de Derrida constituyen un innegable desafío para sus traductores, en el caso de Glas este envite se halla multiplicado a la máxima potencia.

De todos modos, Derrida nunca ha ocultado estas intenciones suyas — todo lo contario- y, como hace en tantas otras ocasiones, muy al principio de Clamor, en una «mirilla» de la columna de Hegel, las deja bien claras: "Que esto no impida utilizar las mismas palabras, palabras homófonas, para conceptos diferentes $y$, con el fin de traicionar la lengua, utilizar homónimos y falsas etimologías para conceptos análogos. / Las palabras están pues desatadas. Enfurecen al diccionario. La lengua no tiene lugar, lugar seguro. El discurso da sentido, pero como un chivato que viene a traicionar toda una red. La traditio entrega (überliefert) el sentido pero para perder la institución en la repetición. Siempre hay que contar con uno de más a cenar en la (es)cena de la lengua. La oposición (lengua/discurso) a su vez se delata a sí misma y delata a todas las demás» (I4).

Puesto que así lo quieres, te voy a poner tres ejemplos concretos de esas interminables dificultades de traducción en Glas. Uno podría ser, precisamente, el de esa scène/cène que aparece en la cita anterior. Pero voy a elegir otros ejemplos. Para entender mejor la primera de estas dificultades que he seleccionado entre tantísimas otras posibles, creo que es conveniente reproducir, en francés, otra de las «mirillas» 
de la columna de Hegel: "Quand on explique Hegel, on est toujours dans un séminaire et on raconte à des élèves: l'histoire du concept, le concept de l'histoire. /Élève: c'est le mot que je traite ici, comme la chose, en tous les sens [una vez más, Derrida confiesa sus objetivos. Los corchetes son míos, C.P.]. / L'élève. Qu'est-ce qu'élever en général (élevage, élévation, élèvement)? Contre quoi pratique-t-on une élève? De quoi relève-t-elle? Que relève-t-elle? Qu'est-ce que relever une élève?» (22). La dificultad, como es obvio, reside en la traducción de un término aparentemente tan corriente y tan inocuo como es l'élève, cuya traducción más evidente es "discípulo/a», «alumno/a» («cadete», si se trata de una escuela militar) pero que cobra a su vez otros sentidos que no pueden por menos que provocar un auténtico rompecabezas para los traductores cuando esta palabra aparece asediada —a nivel, insisto, no sólo semántico-sintáctico sino asimismo fónico y gráfico — por otros términos como élevage (término de ganadería que designa la crianza de los animales, aunque también en vinicultura designa la del vino), élévation (que normalmente significa elevación, ascenso, promoción, aumento pero que asimismo se utiliza en distintos campos como la astronomía, la arquitectura, la medicina, etc.), élèvement (de nuevo elevación, ascenso, etc.) así como por el sustantivo séminaire (que, en francés lo mismo que en español, no significa solamente una reunión académica o una institución eclesiástica sino igualmente un semillero) o por el verbo relever que (además de sus ya múltiples acepciones como levantar, incrementar, detectar, responder, expulsar, reemplazar, incumbir, etc.) está irremediablemente unido a ese sustantivo, relève, con el que Derrida traduce al francés la famosa Aufhebung hegeliana. Un reto insuperable para los traductores abocados a un inevitable fracaso si intentan trasladar al español ese término francés, élève, mediante una sola palabra (nosotros hemos optado por tres) que, por añadidura, habría de mantener (nueva derrota por nuestra parte) esa cercanía fónica y gráfica con los demás términos ya citados (a excepción de «seminario») que rondan en derredor suyo y que, en la mejor de las traducciones (im)posibles, también deberían conservar esa cercanía entre ellos.

Otra vez me he extendido demasiado. Así que tan solo aludiré a otras dos palabras también muy corrientes en francés pero imposibles de traducir como sería lo habitual sin aplanarlas irremediablemente y sin hacer que pasen desapercibidas cuando, precisamente, se trata de dos adverbios como déjà y derrière (este último es igualmente una preposición y un sustantivo) detrás — nunca mejor dicho- de los cuales se esconden y se diseminan (Derrida lo insinúa con frecuencia e incluso, en ocasiones, lo declara abiertamente), a lo largo y a lo ancho de todo Glas, sus siglas (D.J./J.D.) y su apellido.

En cualquier caso, hay que asumir que en toda traducción siempre quedan restos, restos intraducibles, restos que se resisten a cualquier traducción. De no ser así, caeríamos de nuevo en esa trampa tan metafísica y tan denunciada por Derrida como es la de la transparencia y la legibilidad plenas de un texto.

L.F.C.: Muchas fueron los pasajes de especial dificultad. De todos ellos tengo dos en mi memoria que reverberan por su carácter de «actos fallidos» como ejemplos 
claros de una traducción imposible: a uno le dimos, a mi modo de ver, una solución un tanto «salomónica» y al otro una solución que me gustaría calificar como «traición creativa». En el primer pasaje (página 157) aparece el vocablo occurrent simultáneamente en la columna de Genet y en una mirilla; Derrida juega con el término, pero en uno y otro lugar tiene significados distintos (acontecimiento en la columna; tabiques convergentes en la mirilla). Imposible encontrar una misma palabra en castellano para los dos significados. Optamos por mantener la palabra francesa en la mirilla ańadiendo: "[en francés]». No veíamos otra posibilidad si queremos que el lector entienda el sentido de la mirilla, su por qué en ese lugar. En el segundo pasaje (página 273 en la columna de Genet) Derrida, a propósito del lugar del travestimiento, marcado por un «casi», juega con presqu'île (casi isla/ casi él) y péninsule. Imposible trasladar al castellano ese juego fónico. Buscamos otro juego: «casi ínsula/península». Una traición sin duda — nada ha quedado del «casi él»—, pero pensamos que con el nuevo juego que permite nuestra lengua mantenemos de algún modo la «retorcida estructura del travestimiento».

$\mathrm{Al}$ margen de las dificultades, quisiera dejar constancia de dos hechos al menos en cierto modo relevantes, esos dos descubrimientos a los que me refería más arriba: uno relativo al término Ménage que aparece en la página 27I (columna de Hegel, línea 29 de la ed. francesa, y línea 25 de la española) y otro relativo a la palabra montre en la pág. 25I (columna de Genet, línea 2 de la incrustación) que a nuestro modo de ver es una errata. En cuanto al término Ménage ni los traductores de la edición inglesa, ni los de la alemana, ni los de la italiana han acertado en su versión. No se trata del sustantivo común ménage que significa cuidado de la casa, menaje, y otra serie de acepciones de todos conocidas, sino que se trata de un nombre propio, Gilles Ménage, gramático y escritor francés del siglo XVII. Al estar a comienzo de oración la mayúscula del vocablo no ofrecía ninguna pista a los traductores. Nos atribuimos el pequeño y anecdótico mérito de haber hecho la traducción correcta y no haber caído en la trampa de este «señuelo derridiano». Esperamos que los traductores y editores de las citadas versiones lo tengan en cuenta en futuras posibles ediciones. $Y$ en cuanto a la errata de la página 250, no siendo ya posible, desgraciadamente, consultárselo al propio Derrida, nos hemos apoyado en el contexto para deducirla. Nos encontramos con el vocablo montre (muestra), donde debiera decir monte (sube). Esa es nuestra absoluta convicción, ya que aparece en contraposición a descend (baja) («La una sube cuando la otra baja» —está hablando de dos columnas-), contraposición que vuelve a aparecer cinco líneas más abajo. Errata, pues, si no hay razones de más peso que avalen lo contrario o, como dicen los juristas, salvo mejor criterio. Cuestión anecdótica, sin duda —editar Glas sin errata alguna parece tarea imposible_-; pero queremos dejar constancia de ella para conocimiento de los estudiosos e investigadores.

F.V.B.: En clara sintonía con Benjamin, Derrida escribía en un texto poco conocido, Carneros, que el poema — cito de memoria — es una huella cercenada en origen y fin, errante y, por lo tanto, destinada a sobrevivir en los diversos e imprede- 
cibles desciframientos de los lectores por venir. En este orden de consideraciones, los últimos trabajos de De Man apuntaban asimismo a una nueva materialidad de la letra que, precisamente en virtud de lo anterior, hacía historia. Todo ello abunda, según lo veo, en esa im-posibilidad referida, es decir, en el carácter infuturible e inapropiable del texto y sus posibilidades. De ahí su in-traducibilidad.

D.R.: Más que una dificultad me gustaría apuntar la siguiente obsesión: Si ça, además del coloquial y muy frecuente pronombre demostrativo que resulta de contraer «cela»; si ça, además del conjunto de pulsiones inconscientes de corte psicoanalítico; si «ça», pues, pronuncia también «sa», el Saber Absoluto, ¿cómo traducimos la absoluta normalidad de ça sin perder ese otro, y no tan normal, Absoluto que es el Saber? ¿Cómo traducir sin perder, no sólo la polisemia, sino tampoco la crítica, la lectura diseminante, incluso la burla? Obviamente no se puede, pues lo difícil no es sólo traducir el ça de otro en tu supuesta lengua, sino traducir tu ça en el ça del otro, y quizá esa sea la única razón para ponerse inmediatamente a «ello».

A.G.: Me guardo, para concluir, una pregunta ligada al don y a la deuda. Una pregunta que trae el recuerdo imborrable de Paco Vidarte asociado para mí, para siempre, a un Congreso organizado por Mónica Cragnolini en 2006 en Buenos Aires, Por amor a Derrida. En ese encuentro lo recuerdo observándole a un panelista de modos académicos un tanto despreocupados «que para leer a Derrida hay que quemarse un poco más las pestañas». También lo recuerdo recorriendo desde muy temprano, con ansiedad (con esa ansiedad que viene junto con el fervor por un objeto, con esa ansiedad confundida con el entusiasmo y la alegría), las mesas de los expositores del congreso, en muchas ocasiones desatendidas por las grandes firmas. Eso en lo que él ya, a su corta edad, se había convertido: una firma, una gran firma. Tal vez digo una obviedad: hoy en Argentina los trabajos del Paco son una referencia insoslayable en los estudios de género y queer. Insoslayables no sólo por sus planteos sino por su llevar al límite la materialidad de la lengua y de lo decible desde los claustros. Considerando ese carácter intempestivo, implacable, agudo e intransigente de sus intervenciones, me permito preguntarte Cristina si recordás algo en particular de sus aportes o de sus inquietudes o de sus expectativas respecto de la traducción de este texto intempestivo, agudo e intransigente de Derrida. Un texto que, incontestablemente, vuelve sobre su figura, y la actualiza (como la actualizan ustedes recordando su participación en la tarea y trayéndolo entonces, en parte, otra vez, a la vida).

C.P.: Como también he dicho ya anteriormente, yo no compartí grupo de traducción con Paco durante el poco tiempo que él estuvo en este proyecto. Por lo tanto, creo que otros de los entrevistados aquí pueden contestar mucho mejor que yo cuáles pudieron ser las aportaciones, inquietudes o expectativas de Paco respecto a la traducción de Glas al espańol. 
A.G.: Muchas gracias por las respuestas que, como siempre que conversamos, dejan resto para otras por-venir: en principio, alrededor de los términos «fantasía» $\mathrm{y}$ «de $(s)$ construcción». 